\title{
PRELIMINARY STUDY ON COMBUSTION AND OVERALL PARAMETERS OF SYNGAS FUEL MIXTURES FOR SPARK IGNITION COMBUSTION ENGINE
}

\author{
Rastislav Toman ${ }^{a, b, *}$, Marián Polóni $^{a}$, Andrej ChríbiK $^{a}$ \\ ${ }^{a}$ Institute of Transport Technology and Design, Faculty of Mechanical Engineering, Slovak University of \\ Technology in Bratislava, Námestie Slobody 17, 81231 Bratislava, Slovak Republic \\ ${ }^{b}$ Department of Automotive, Combustion Engine and Railway Engineering, Faculty of Mechanical Engineering, \\ Czech Technical University in Prague, Technická 4, 16607 Prague 6, Czech Republic \\ * corresponding author: rastislav.toman@fs.cvut.cz
}

\begin{abstract}
This paper presents a numerical study on a group of alternative gaseous fuels - syngases, and their use in the spark-ignition internal combustion engine Lombardini LGW 702. These syngas fuel mixtures consist mainly of hydrogen and carbon monoxide, together with inert gases. An understanding of the impact of the syngas composition on the nature of the combustion process is essential for the improvement of the thermal efficiency of syngas-fuelled engines. The paper focuses on six different syngas mixtures with natural gas as a reference.

The introduction of the paper goes through some recent trends in the field of the alternative gaseous fuels, followed by a discussion of the objectives of our work, together with the selection of mixtures. Important part of the paper is dedicated to the experimental and above all to the numerical methods. Two different simulation models are showcased: the single-cylinder 'closed-volume' combustion analysis model and the full-scale LGW 702 model; all prepared and tuned with the GT-Power software.

Steady-state engine measurements are followed by the combustion analysis, which is undertaken to obtain the burn rate profiles. The burn rate profiles, in the form of the Vibe formula, are than inserted into the in-house developed empirical combustion model based on Csallner-Woschni recalculation formulas. Its development is described in the scope as well. The full-scale LGW 702 simulation model, together with this empirical combustion model, is used for the evaluation of engine overall performance parameters, running on gaseous fuel mixtures. The analysis was done on engine full load and stoichiometric mixture conditions only.
\end{abstract}

KEYWORDS: spark-ignition piston combustion engine; alternative gaseous fuel; syngas; combustion modelling.

\section{INTRODUCTION}

Syngas or a 'synthesis gas' is a summarizing name for the gaseous fuel mixture containing combustible and relatively high inert gas content. The main combustible components of these fuels are always hydrogen $\left(\mathrm{H}_{2}\right)$ and carbon monoxide $(\mathrm{CO})$. Methane $\left(\mathrm{CH}_{4}\right)$, carbon dioxide $\left(\mathrm{CO}_{2}\right)$ or nitrogen $\left(\mathrm{N}_{2}\right)$ and other minor hydrocarbon constituents (ethane, propane, butane etc.) can then constitute the rest of the fuel mixture. The syngas is produced from various feedstock, for example, coal, biomass, organic waste, tar or natural gas, by a variety of production processes such as gasification or pyrolysis [1 4]. The exact composition of a syngas is then given by its production process and feedstock used. Resulting syngas mixture is a solid alternative fuel in the field of power generation by cogeneration units.

The topic of alternative gaseous fuels for the use in cogeneration units is of growing interest in recent years. An extensive research has been done to make the spark-ignition combustion engines fuelled by natural gas (NG) competitive to diesel engines, with a special focus on exhaust gas emissions. Experimental studies dealing with the effect of exact NG composition, lean burn conditions, different EGR levels, and the use of 3-way catalytic converters on the overall engine parameters and emissions were presented [5-7]. More recent experimental studies focus also on the combustion characteristics and emission effects of different dilution gases on the NG engine under constantconditions (load, speed and spark advance) stoichiometric operation [8]. Nevertheless, the general trend is to use the experiments for a model validation purpose, and then to employ the model for a numerical investigation and optimization of ICE running in the cogeneration unit 9. Regarding the syngas mixtures, the impact of the syngas composition on the combustion characteristics in the ICE [10], or in more detail on the laminar and turbulent flow velocities is prominent [11]. Apart from these experimental and numerical studies, the authors in 12 presented a combined experimental, numerical, and theoretical study on the engine performance running on four gaseous mixtures: two different syngas mixtures with comparison to the NG and hydrogen. After the measurements, 


\begin{tabular}{lcccccccc}
\hline Parameter & Unit & NG & SG6 & SG18 & SG21 & SG22 & SG23 & SG31 \\
\hline CH4 & {$[\mathrm{vol} \%]$} & 96.033 & 20 & 0 & 0 & 10 & 0 & 10 \\
C2H6 & {$[\mathrm{vol} \%]$} & 2.036 & 0 & 0 & 0 & 0 & 0 & 0 \\
C3H8 & {$[\mathrm{vol \% ]}$} & 0.599 & 0 & 0 & 0 & 0 & 0 & 0 \\
nC4H10 & {$[\mathrm{vol} \%]$} & 0.196 & 0 & 0 & 0 & 0 & 0 & 0 \\
nC5H12 & {$[\mathrm{vol \% ]}$} & 0.001 & 0 & 0 & 0 & 0 & 0 & 0 \\
H2 & {$[\mathrm{vol} \%]$} & 0 & 20 & 10 & 20 & 20 & 30 & 25 \\
CO & {$[\mathrm{vol \% ]}$} & 0 & 30 & 30 & 20 & 10 & 10 & 20 \\
CO2 & {$[\mathrm{vol} \%]$} & 0.283 & 25 & 10 & 10 & 10 & 10 & 20 \\
N2 & {$[\mathrm{vol \% ]}$} & 0.794 & 5 & 50 & 50 & 50 & 50 & 25 \\
\hline LHV & {$[\mathrm{kJ} / \mathrm{kg}]$} & 48796 & 12027 & 4043 & 4298 & 6762 & 4620 & 8385 \\
A/F Ratio & {$[\mathrm{kg} / \mathrm{kg}]$} & 16.96 & 3.66 & 1.01 & 1.12 & 2.08 & 1.26 & 2.49 \\
Molar mass & {$[\mathrm{kg} / \mathrm{kmol}]$} & 16.74 & 24.42 & 27.01 & 24.41 & 23.22 & 21.81 & 23.52 \\
Density & {$\left[\mathrm{kg} / \mathrm{m}^{3}\right]$} & 0.696 & 0.998 & 1.104 & 0.998 & 0.949 & 0.892 & 0.961 \\
H/C & {$[1]$} & 3.91 & 1.6 & 0.5 & 1.33 & 2.67 & 3 & 1.8 \\
O/C & {$[1]$} & 0.01 & 1.07 & 1.25 & 1.33 & 1 & 1.5 & 1.2 \\
\hline & & & & & & & & \\
\hline
\end{tabular}

TABLE 2. Basic physical and chemical properties of the used fuel mixtures.

\begin{tabular}{lcccc}
\hline & Unit & Group 1 & Group 2 & Group 3 \\
\hline CH4 & {$[$ vol $\%]$} & $0-50$ & $0-20$ & $0-20$ \\
H2 & {$[$ vol $\%]$} & $10-50$ & $10-30$ & $5-45$ \\
CO & {$[$ vol $\%]$} & $20-40$ & $10-30$ & $10-50$ \\
CO2 & {$[$ vol $\%]$} & 25 & 10 & 20 \\
N2 & {$[$ vol $\%]$} & 5 & 50 & 25 \\
\hline
\end{tabular}

TABLE 1. Range of syngas groups composed with various inert gas concentrations (in vol\%).

combustion analysis was undertaken, with crank angle resolved in-cylinder turbulence and flame propagation plotted onto so-called 'Bradley diagram', to explain the variation of the engine performance parameters.

Our own previous work in the facility of Slovak University of Technology in Bratislava was mostly focused on the experimental research of NG based fuels, such as NG mixtures with hydrogen [13] or $\mathrm{CO}_{2}$ [14] $-\mathrm{H}_{2} \mathrm{NG}$ and $\mathrm{CO}_{2} \mathrm{NG}$. However, here presented literature on alternative gaseous fuels show many opportunities for a simulation too. The principal opportunity is that a well-tuned numerical model allows for the extensive optimization of ICE parameters, for example, ignition or valve timing, as it was the case in [9]. A numerical model may also guide the experiments. Other possibility is to employ the advanced predictive combustion models to model and study the ICE combustion process for different fuel mixtures [12]. Finally, the simulation tools also shorten the development experimental loops and subsequently reduce the time and costs of the research and real-life application of alternative fuels into the cogeneration units. Recapitulating all discussed benefits, we have decided to enhance our research activities with simulation tools.

There are two main objectives of this paper. First objective is the preliminary analysis of the main combustion parameters for the different syngas mixtures, with a GT-Power combustion analysis model. This combustion analysis model processes the measured in-cylinder pressure data together with other important measured quantities. The second objective of this paper is to get an estimation of steady-state engine performance parameters powered by different stoichiometric syngas mixtures under full load and different engine speeds (1200 to 2500 RPM sweep) by simulation. To meet this second objective a GT-Power full-scale simulation model of Lombardini LGW 702 engine was prepared and tuned, with a proper in-house combustion model.

\subsection{Selected fuel miXtures}

In the early phases of our research on syngas mixtures, we determined thirty-five various syngas mixtures, based on the knowledge of real-life syngas produced industrially, with the aim to cover the widest range of possible mixture compositions. For a better classification of these compositions, the mixtures are sorted into three different groups by the inert gas concentration: with 30,45 , and 60 volume percent of the inert gas. The rest are combustible components (Table 1). Group 1 contains seventeen various syngas mixtures with relatively small amount of inert gases. Group 2 contains only six mixtures and Group 3 twelve different mixtures.

For the preliminary analysis, only six of the total number of thirty-five various syngas mixtures are presented in this paper: one syngas from Group 1 and one from a Group 3 as a representative sample. From the Group 1 it is syngas 6 (further labelled SG6) and from Group 3 the SG31. In this paper, a Group 2 syngas mixtures are of a special interest, due to their very high inert gas content. Therefore, four of them are covered: the SG18, the SG21, the SG22, and the SG23. The basic physical and chemical properties of these six fuel mixtures are summarised in Table 2 . In 


\begin{tabular}{lc}
\hline & LGW 702 \\
\hline Bore & $76 \mathrm{~mm}$ \\
Stroke & $77.6 \mathrm{~mm}$ \\
Cylinders & $2 ;$ in line \\
Engine displacement & $704 \mathrm{~cm}^{3}$ \\
Compression ratio & $12: 01: 00$ \\
Valves per cylinder & 2 \\
IVO & $340^{\circ} \mathrm{CA}$ \\
IVC & $599^{\circ} \mathrm{CA}$ \\
EVO & $147^{\circ} \mathrm{CA}$ \\
EVC & $386{ }^{\circ} \mathrm{CA}$ \\
\hline
\end{tabular}

TABle 3 . Tested engine main dimensions.

our experimental and simulation study of syngas mixtures, we use the NG distributed in Slovak Republic (96\% of methane) as a reference fuel mixture, with the real composition used during the measurements.

A high inert gas content in syngas mixtures lowers the LHV, which should then lead to lower maximum pressures, temperatures, lower overall performance parameters, and high fuel consumption. Inert gases slow down the burning process, whereas hydrogen does the opposite. Thus, different burn duration is expected compared to the NG. The best performance properties should be reached by the SG6, because of its high LHV compared to the other syngas mixtures.

\section{EXPERIMENTAL METHODS}

All the experimental data were acquired on a steadystate test bench in the facility of STU Bratislava on a small, two-cylinder, water-cooled, naturally-aspirated, spark-ignition engine Lombardini LGW 702 [15]. This engine was rebuilt from the compression ignition Lombardini variant LDW 702. Thus, it had to be fitted with an ignition system instead of fuel injectors and new lower compression ratio pistons. The combustion chamber has a simple geometry with a flat cylinder head and a centred piston bowl. The main geometrical parameters of LGW 702 are listed in Table 3 (the cam timing zero reference point is the firing TDC). A fuel mixture is prepared in a diffuser-type mixer.

Our experimental test bench is equipped with an acquisition system measuring engine torque and speed, overall pressures and temperatures, air and fuel flows, together with the exhaust gas composition. The ICE is then equipped with one spark plug integrated piezoelectric pressure transducer, for the in-cylinder pressure measurement, together with a crank angle encoder. Currently, we measure the pressure with a constant frequency of $66 \mathrm{kHz}$ and the crank angle encoder only determines the TDC. In the future measurement, a full 'Three-pressure-analysis' (TPA) capability will be introduced into the test bench, together with more precise crank angle related pressure measurement.

All fuel mixtures in this study were experimentally tested under full load and constant engine speed of 1500 RPM. The spark timing of $27^{\circ} \mathrm{CA}$ BTDC and stoichiometric air-to-fuel ratio $(\lambda=1)$ were kept constant. The latter due to the use of the 3 -way catalytic converter.

\section{NumericAL METHODS}

\subsection{Combustion analysis}

The combustion of fuel mixture in a combustion engine is best understood by studying the burn rate profile. A burn rate profile can be obtained from a measured in-cylinder pressure by a so-called 'reverse run' simulation method. In a 'reverse run' method, the in-cylinder pressure is an input for the analysis; the burn rate is then an output. In a normal simulation, the 'forward run', it is vice versa. These methods are also implemented in the GT-Power simulation tool. A great advantage of using the GT-Power is that both forward and reverse runs use the same approach of two-zone combustion modelling, without any simplifying assumptions on the side of thermodynamics or chemistry [16.

Then in the GT-Power, there are two approaches of how to use the 'reverse run' cylinder analysis. The first one: the 'stand-alone burn rate calculation' ( $1 \mathrm{Cyl}$ ) uses only an in-cylinder measured pressure; together with a few basic cycle averaged results (as volumetric efficiency), engine cylinder geometry, cylinder wall temperatures, heat transfer model, and initial conditions. This model is not connected to any upstream or downstream 1D flow components, therefore, these initial conditions represent the trapped conditions at the IVC and need to be estimated from measurement. The second approach is the already mentioned TPA, which also requires measured intake and exhaust pressures. The authors in 17] show, that the TPA approach is more accurate, since there is no need of parameter estimation: the trapped conditions at the IVC are directly simulated from the 1D flow components.

Since, in our research facility, the TPA is not available, we use a simple $1 C y l$ approach and for the initialization of the closed-volume cycle we use the trapped quantities from a full-scale engine model.

In general, the error in a calculation of the burn rate from the measured in-cylinder pressure is always present. There are potential errors in the in-cylinder pressure measurement, initialization inputs estimation, or also from other sub-models, such as for the incylinder heat transfer coefficient calculation. In every combustion analysis run, the GT-Power reports some automatic 'consistency checks' that help to identify the source of the error. These 'consistency checks' are listed in [16] and we used them during our analysis to compensate the lack of the TPA or inaccuracies in our measurement. The most important of the 'consistency checks' is the 'Fuel energy (LHV) Multiplier' ( $L H V$ Multiplier). When the $L H V$ Multiplier value differs from unity, it means that the input energy in the simulation system is different from the needed one to follow the measured in-cylinder pressure curve. 


\subsection{Combustion modelling}

One of the objectives of this study is to estimate correctly the engine performance parameters under different engine speeds. But the output of the combustion analysis - a burn rate profile - cannot be universally used for different engine speeds, since the profile is deformed substantially with changed operating conditions [18]. Various possibilities of either empirical or phenomenological combustion models can be used inside the GT-Power.

Empirical models proposed in [18, 19] are based on an extensive measurement database. The authors used simple recalculation multipliers of significant burn points, dependant on engine speed, load, spark advance, $\lambda$, residual gas fraction, intake pressure, and temperature. Other option is the GT-Power's predictive phenomenological turbulent combustion model EngCylCombSITurb (or SITurb), based on [20, 21]. Both the empirical and phenomenological options need a number of accurately measured engine operation points. The advantage of the empirical combustion models is that they are easy to implement, but their downside is that they work well only inside the tuned operating range. The SITurb model is even more demanding on the side of the tuning process and input data, requiring the swirl and tumble characteristics of the intake valves, together with the complete combustion chamber geometry. However, the SITurb can then be used also for the reasonable combustion prediction outside of the tuned operating range. This was shown in 22] for the gasoline fuel. The SITurb was likewise successfully used for syngas combustion modelling in [12.

In our study, we have decided to build an empirical combustion model (Empirical model) by combination of empirical Vibe formula model EngCylCombSIWiebe 23

$$
x_{b}=1-\exp -a\left(\frac{\alpha-\alpha_{0}}{\Delta \alpha}\right)
$$

and recalculation formulas proposed by Csallner and Woschni 24. Csallner-Woschni formulas incorporate the effect of different engine operating point (engine speed, load, $\lambda$, spark-advance, and residual gas fraction) on the combustion characteristics. Vibe formula requires three important parameters to be set: Burn Duration (10-90\% MFB), Vibe Shape Exponent $m$ (1), and CA50, so the crank angle at $50 \%$ mass fuel burned (Figure 1: a comparison of three different gas mixtures at full load, $\lambda=1$ and 1500 RPM for illustration). In our Empirical combustion model, the Vibe formula parameters - outputs from a single operation point combustion analysis - are automatically adjusted by Csallner-Woschni formulas, to obtain a new steady-state operating point values. Regarding the Vibe Shape Coefficient, we assume its value to be constant for the particular syngas and the whole operating range. This simplification is also justified and used by the author of [25], who states that the

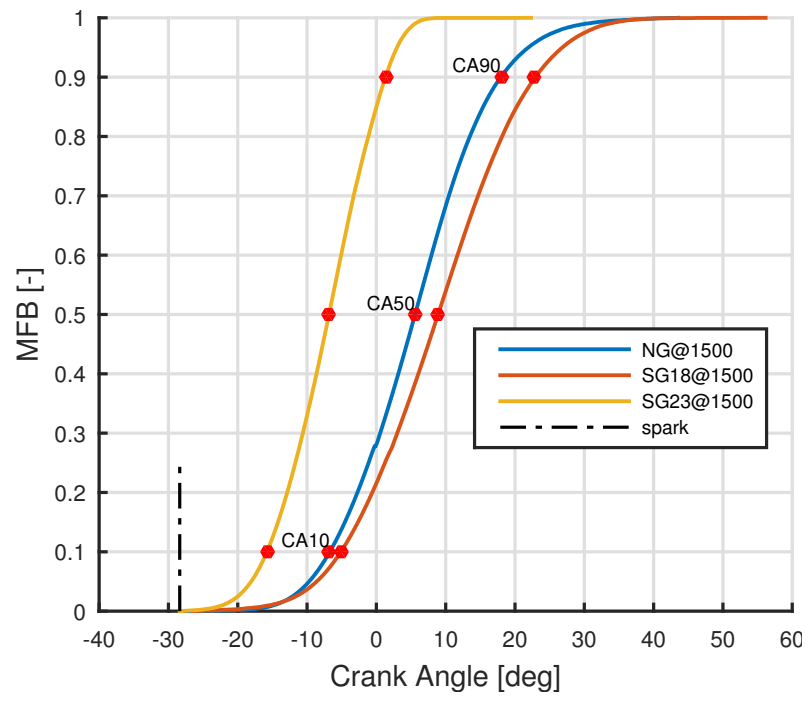

FiguRE 1. Vibe curves and significant burning points for different fuel mixtures at constant spark advance and engine speed.

change in the shape coefficient does not affect the overall result.

It is worth to emphasise that the Csallner-Woschni recalculation formulas have not been verified for this preliminary analysis. However, they are necessary for our future simulation activities.

\subsection{Full scale engine simulation}

Lombardini LGW 702 GT-Power full-scale (Full) model includes all relevant engine cylinder and cranktrain dimensions. Full model further includes measured engine speed dependant friction losses of the whole LGW 702 assembly and measured necessary intake/exhaust flow coefficients. The Empirical combustion model from the previous section is included in the Full model. The in-cylinder heat transfer coefficient calculation is carried out by WoschniGT model [16] that closely emulates the classical Woschni correlation without swirl, as described in [26].

The base Full model was tuned after the initial modelling. The tuning process was split into two steps. We focused the first step on the engine integral parameters: brake torque, BSFC, and volumetric efficiency. Full model results were adjusted to the set of the NG full load steady-state measurement data [27, which does not include the in-cylinder pressure curves. There was a small uncertainty on the exact NG composition (arising from a possible grid gas composition variation that is controlled by a public regulation), but the spark timing and $\lambda$ were known for each operating point. Other combustion model parameters had to be reasonably estimated. Some of the component flow and heat transfer characteristics were manually adjusted to get an overall agreement with measured data (especially volumetric efficiency). Our requirement was to reach the error values lower then $\pm 5 \%$. This requirement was fulfilled (Figure 2p. 


\begin{tabular}{lcc}
\hline Minimized target function $X_{k}$ & Weight factor $\alpha_{k}$ & Optimal solution \\
\hline Average pressure difference & 0.35 & 0.179 \\
Maximum pressure difference & 0.15 & 0.224 \\
Average LHV multiplier error & 0.35 & 0.005 \\
Maximum LHV multiplier error & 0.15 & 0.008 \\
\hline
\end{tabular}

TABLE 4. Criterial function weight factor from Equation (3) and optimal solution values.

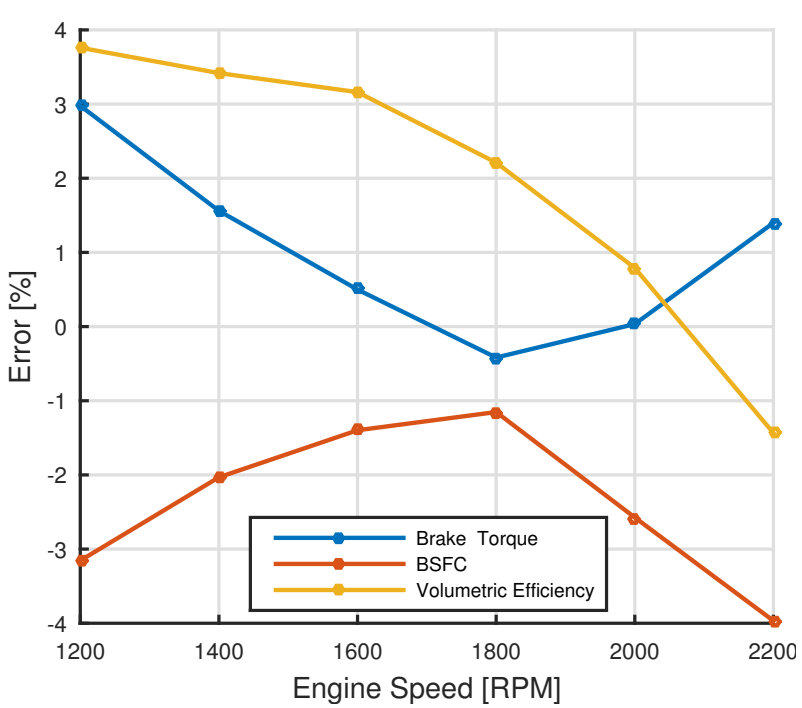

Figure 2. Errors on brake torque, the BSFC and volumetric efficiency prediction after first step calibration (simulation - measurement).

The second Full model tuning step was focused on in-cylinder quantities, mainly in-cylinder pressure curve agreement with measurement and the already mentioned $L H V$ Multiplier. We used a set of seven full load, $\lambda=1$ operation points (engine speeds 1200 2200 RPM), with a pure methane as a fuel. Methane properties are well known and were inserted into our model, together with measured in-cylinder pressure. Then, since the measurement errors and uncertainties are always present, we appointed three main possible sources:

- effective Compression Ratio, which can be different from the geometrical compression ratio due to blowby, wrong geometry estimation, or material wear;

- Convection Multiplier from the heat transfer model is generally not a unity [16] and needs to be adjusted;

- TDC Error parameter, that introduces a possible inaccuracy in the measurement TDC determination.

These three tuning parameters can be tuned manually, or as in our case: coupled to an external optimization software. We performed this multi-criterial optimization task using the genetic algorithm NSGAII [28]. As an optimization criterion, four target functions from Table 4 were minimized. The pressure difference is evaluated by a simple formula (2) that compares the measured and simulated pressure curve.

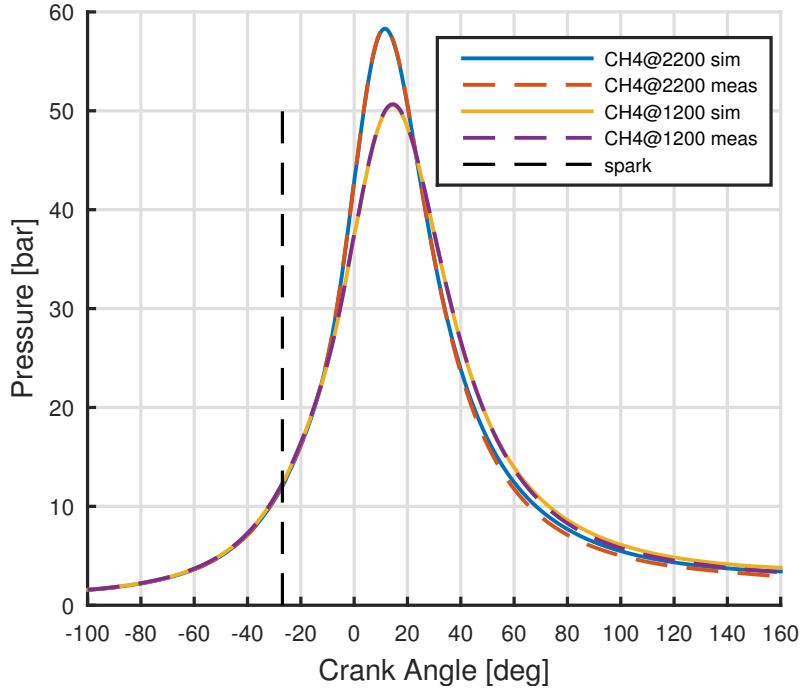

FiguRE 3. Comparison of measured and simulated pressure curves for the optimal solution.

Other quantities, for instance, the mixture air excess $\lambda$, were assumed as correctly determined, and therefore were not included into the multi-criterial optimization:

$$
\Delta p=\frac{1}{\alpha_{\text {end }}-\alpha_{\text {start }}} \int_{\alpha_{\text {start }}}^{\alpha_{\text {end }}}\left|p_{\text {meas }}-p_{\text {sim }}\right| \mathrm{d} \alpha .
$$

The Pareto Frontier results set was then processed by a criterial function (3). The fraction $\frac{X_{k}}{X_{k, \max }}$ represents the normalization, so that different functions $X_{k}$ can be combined into a single equation:

$$
F=\sum_{k=1}^{n} \alpha_{k} \frac{X_{k}}{X_{k, r \operatorname{mmax}}}
$$

Table 4 also shows the chosen weight factors $\alpha_{k}$ of the four target functions and the values of the 'optimal solution'. The 'optimal solution' determined the values for the three tuning parameters. Figure 3 displays the comparison of measured and simulated pressure curves of two operating points (methane; full load; $\lambda=1 ; 1200 \mathrm{RPM}$ and $2200 \mathrm{RPM}$ ) of the 'optimal solution'. In addition, some different weight factors were tested. However, if the weight factors ratio between the average and maximum errors is kept, the final 'optimal solution' is not affected by the weight factors change. 


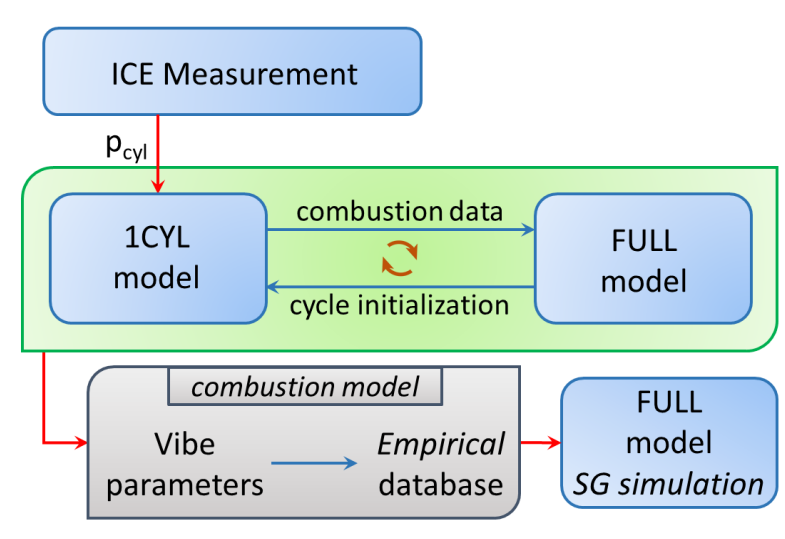

FiguRE 4. Schematic simulation procedure of a new syngas fuel mixture.

\begin{tabular}{lc}
\hline Verification function & Syngas set \\
\hline Average pressure difference & 0.308 \\
Maximum pressure difference & 0.594 \\
Average LHV multiplier error & 0.022 \\
Maximum LHV multiplier error & 0.033 \\
\hline
\end{tabular}

TABLE 5. Verification parameters from the syngas combustion analysis.

\subsection{Simulation Procedure}

The general simulation procedure of a new syngas mixture (or other gaseous mixture) is schematically represented on Figure 4 This procedure starts with a combustion analysis of the measured pressure data $\left(p_{\text {cyl }}\right)$. A simulation loop between the 1 Cyl combustion analysis model and the Full model has to be iterated, until the combustion analysis results converge. This is because the $1 C y l$ model needs the initialization parameters from the Full model simulation, and these are affected by the combustion model parameters. It normally takes two to three manual iterations to reach the same result of the combustion analysis.

Full model overall results have to be always compared against the measurements and also the $1 \mathrm{Cyl}$ simulated in-cylinder pressure and burn rate, to make sure everything is set up correctly.

After that, the combustion analysis results are prepared to be used as an input for the Empirical combustion model. With the Empirical combustion model extended by the data from the new syngas mixture, the simulation or optimization of a new engine operating points on Full model can start. We used this particular procedure in this presented project. Empirical combustion model was extended with the combustion analysis and then used for the simulation of the whole engine speed sweep (1200 to 2500 RPM), full load, and $\lambda=1$. We carried out the spark-timing optimization for each operating point of all simulated mixtures in accordance with the aim of this project, which is to get the insight on maximum possible overall engine parameters.

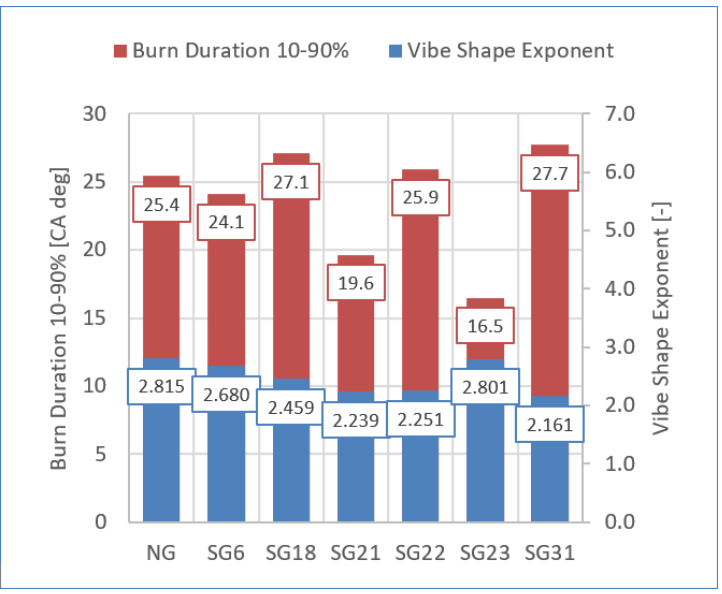

Figure 5. Burn Duration 10-90\% and SI Vibe Burn Exponent comparison of the 6 SGs with the NG fuel for the LGW 702 engine single-cylinder combustion analysis.

\section{Simulation Results}

\subsection{Combustion analysis Results}

The syngas (and the NG reference) measurement set was measured right after the methane set, which was used for the model tuning. Therefore, the same TDC Error correction and other parameters were also used in the syngas combustion. Table 5 shows the verification functions from the $1 \mathrm{Cyl}$ combustion analysis on syngas set. Values in Table 5 are acceptable, although higher than those from Table 4 for the originally tuned methane set. This is probably caused by a relatively small set (seven operation points), that was used for the multi-criterial optimization, or other uncertainties in measurement.

The $1 C y l$ combustion analysis determined the values of the Vibe Shape Exponent and Burn Duration $10-90 \%$ for each mixture (Figure 5). The values of the NG were checked with past research results and match them well.

Nevertheless, the individual impact of the fuel mixture components and their interaction together in different mixtures has to be studied separately by a measurement and combustion analysis, which is not of interest in this presented paper.

In the case of the analysis of the 6 different syngas compositions and natural gas, it is very hard to conclude the attribution of individual mixture components, as these can cancel out each other. The author in 19 shows a similar trend: the addition of $\mathrm{H}_{2}$ speeds-up the burning process and the inert gases $\mathrm{N}_{2}$ and $\mathrm{CO}_{2}$ have the opposite effect. The impact of $\mathrm{CO}_{2}$ is greater than the impact of $\mathrm{N}_{2}[8$. From the combustion analysis results (Figure 5 ) the effect of the $\mathrm{H}_{2} / \mathrm{CH}_{4}$ ratio, with other mixture components constant, for the SG22 and SG23 is visible: more H2 content over $\mathrm{CH}_{4}$ leads a to faster burn. The same can be said with $\mathrm{H}_{2} / \mathrm{CO}$ for the SG18 and SG21: again more $\mathrm{H}_{2}$ content leads to a faster burn. 


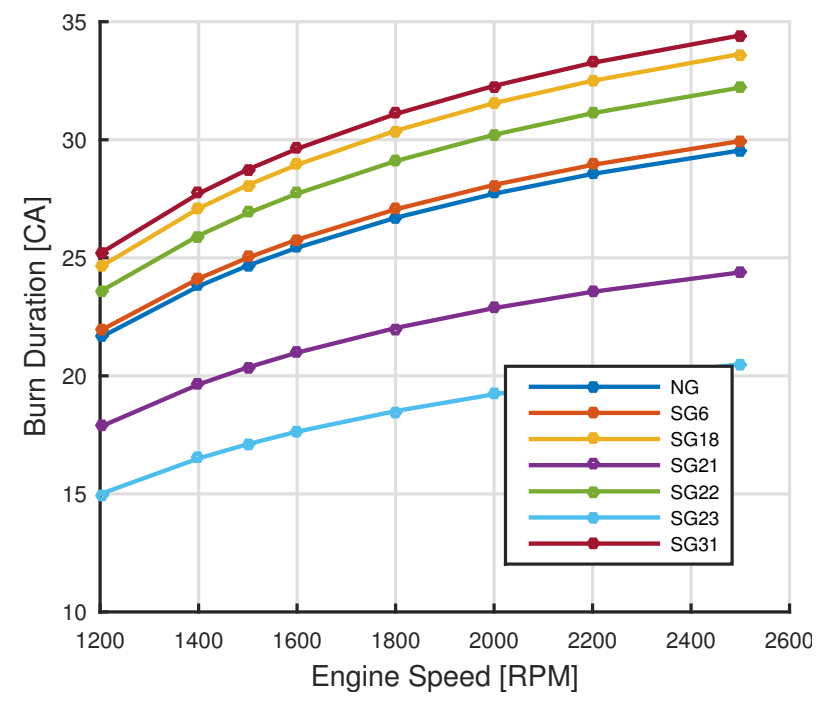

Figure 6. Optimized CA50 position comparison of 6 SGs with NG fuel for LGW 702 engine.

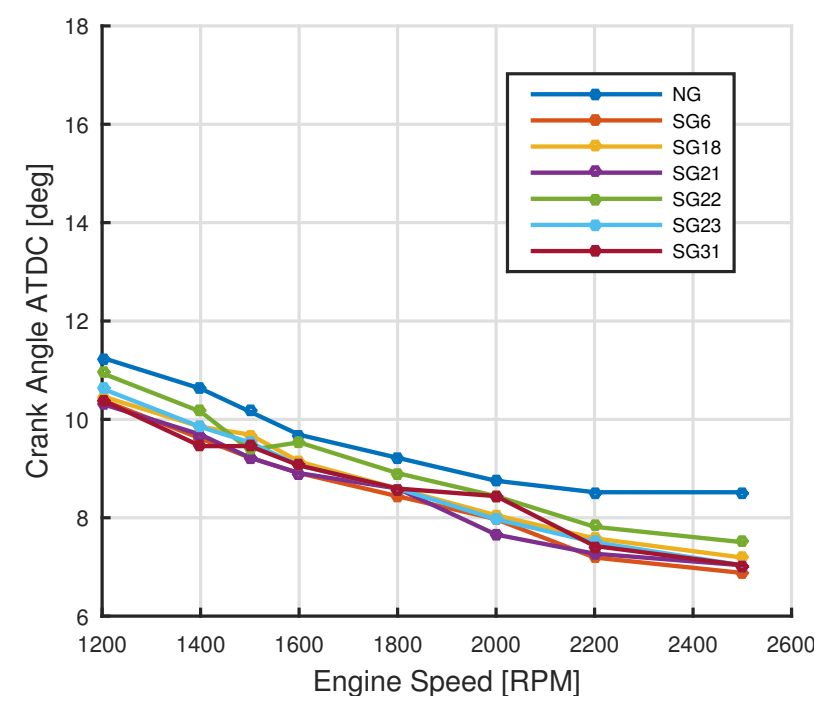

Figure 7. Burn duration 10-90\% MFB comparison of the 6 SGs with the NG fuel for the LGW 702 engine.

\subsection{Full MOdEL RESUlts}

The final Full model simulations of the fuel mixtures SG6, SG18, SG21, SG22, SG23, SG31, and the NG reference on the LGW 702 engine were carried out in a range of engine speeds from 1200 to $2500 \mathrm{RPM}$, at full load, $\lambda=1$, and optimal CA50.

The optimized CA50 position for each fuel mixture is shown on Figure 6. For higher engine speeds, the position of combustion centre shifts slightly towards the TDC. The Empirical combustion model automatically adjusts Burn Duration for each mixture (Figure 7), prolonging the Burn Duration with growing engine speed. The values at $1500 \mathrm{RPM}$ are matching the trends from Figure 5: the SG21 and SG23 show faster burn in the whole RPM region; the SG18, SG22, and SG31 slow burn; and the SG6 with the NG are balanced in the middle.

Figure 8 shows the comparison of the IMEP. As expected, the IMEP values, in general, for all the

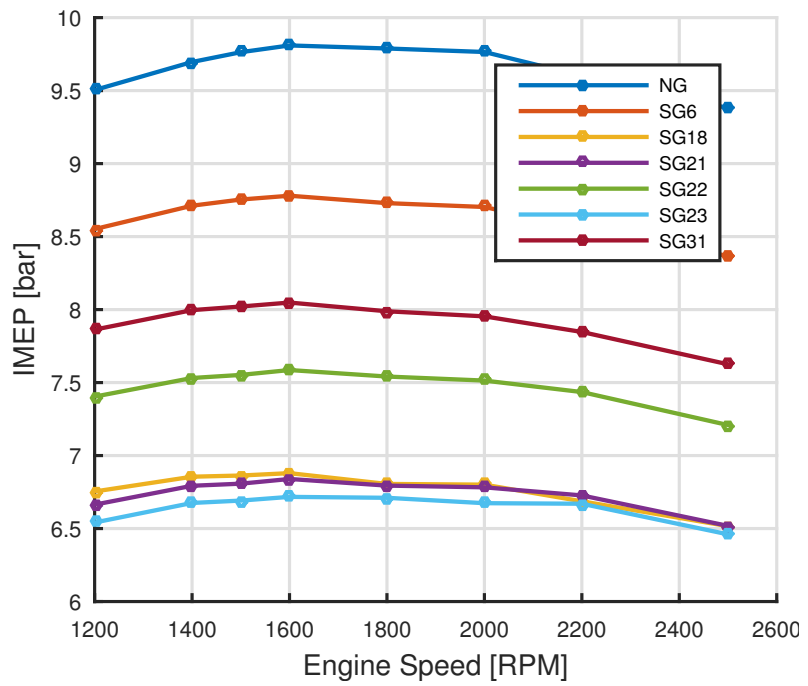

Figure 8. IMEP comparison of the 6 SGs with the NG fuel for the LGW 702 engine.

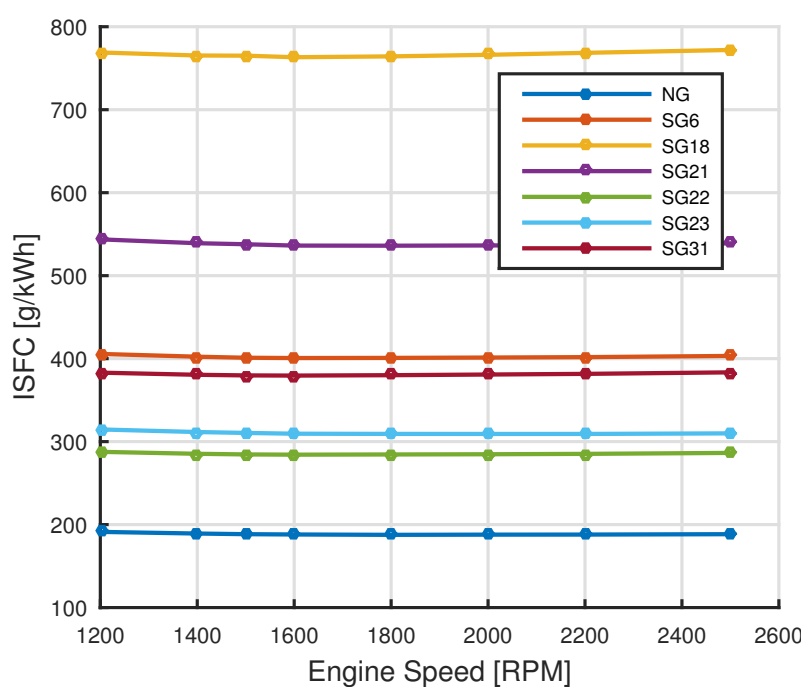

Figure 9. ISFC comparison of the 6 SGs with the NG fuel for the LGW 702 engine.

SGs are below the NG, for instance, for the SG6, it is approximately 1.2 bar, but for the Group 2 SG18, SG21, and G23 with the lowest LHV, it is around 3 bars, so more than $30 \%$.

The obvious increment of the ISFC for syngas mixtures compared to the NG is displayed in the following Figure 9 Values of the ISFC for the NG are below 200 $\mathrm{g} / \mathrm{kWh}$; for the SG22 it is around $285 \mathrm{~g} / \mathrm{kWh}(+45 \%)$; for the SG21 already $535 \mathrm{~g} / \mathrm{kWh}(+180 \%)$, and the most extreme case is the SG18 with a difference of more than $+400 \%$, compared to the NG.

The figures for the IMEP and the ISFC (Figure 8 and Figure 9), show the indicated values, that are directly derived from the engines $\mathrm{p}-\mathrm{V}$ diagram. The IMEP and the ISFC are independent on the ICE operating losses (friction, etc.), therefore, they can be considered as an appropriate relative measure of engine overall operation parameters. The indicated efficiency (indicated work per cycle over input energy 


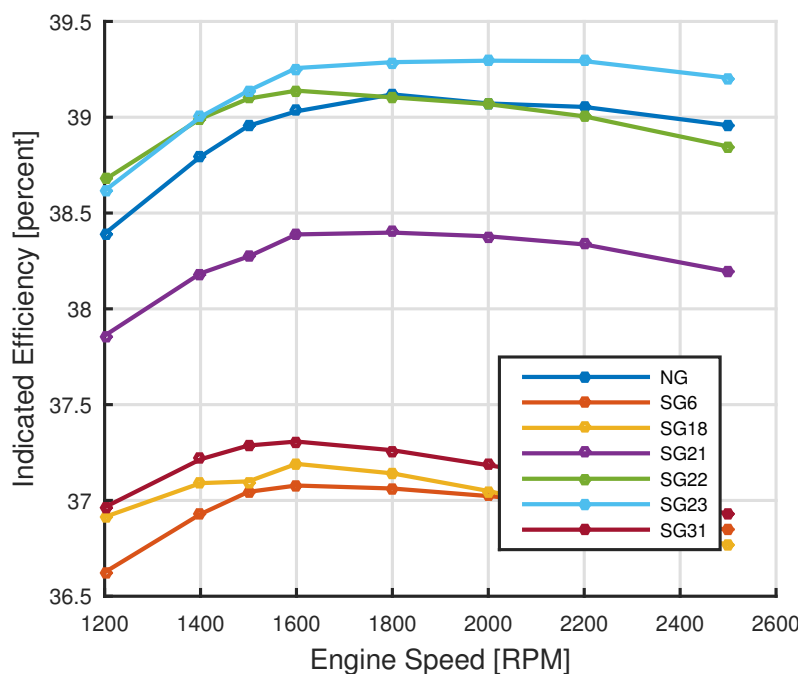

FIGURE 10. Indicated Efficiency comparison of the 6 SGs with the NG fuel for the LGW 702 engine.

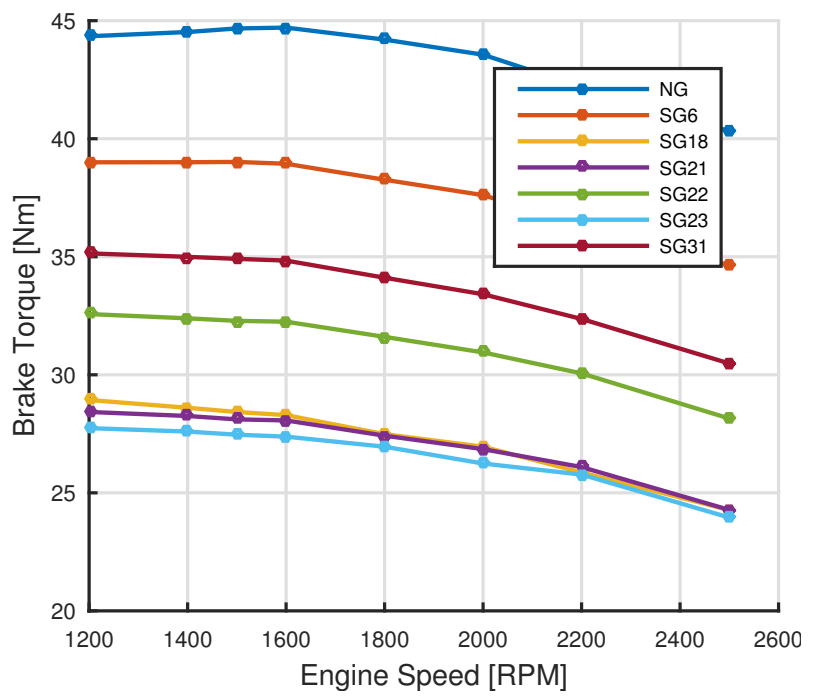

FiguRE 11. Brake torque comparison of 6 SGs with NG fuel for LGW 702 engine.

in fuel [16]) itself is shown on Figure 10 In general, the indicated efficiency differences between the mixtures are not significant. Figure 11 with the brake torque output illustrates what torque values can be expected during experimental testing on the engine test-bench. Here, the impact of the fuel LHV parameter on the brake torque output is visible: the low LHV syngas mixtures also show low brake torque output.

Regarding the cycle data, there are three important values: maximum cycle pressure (Figure 12), maximum cycle temperature (Figure 13), and maximum cycle pressure crank angle position (Figure 14).

These three figures also show the importance of the fuel LHV parameter: the low LHV syngas mixtures also show low maximum cycle pressure and lower maximum cycle temperature. With the higher fuel $\mathrm{LHV}$, it is vice versa.

For the $\mathrm{NO}_{x}$ production, it is crucial that for the SG fuels, the maximum cycle temperature values are

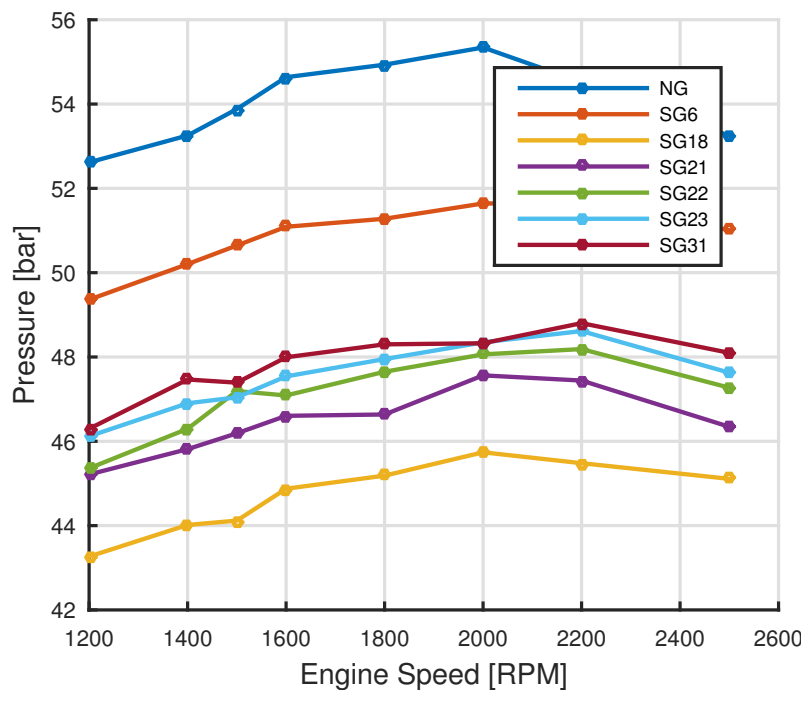

Figure 12. Maximum Cycle Pressures comparison of the 6 SGs with the NG fuel for the LGW 702 engine.

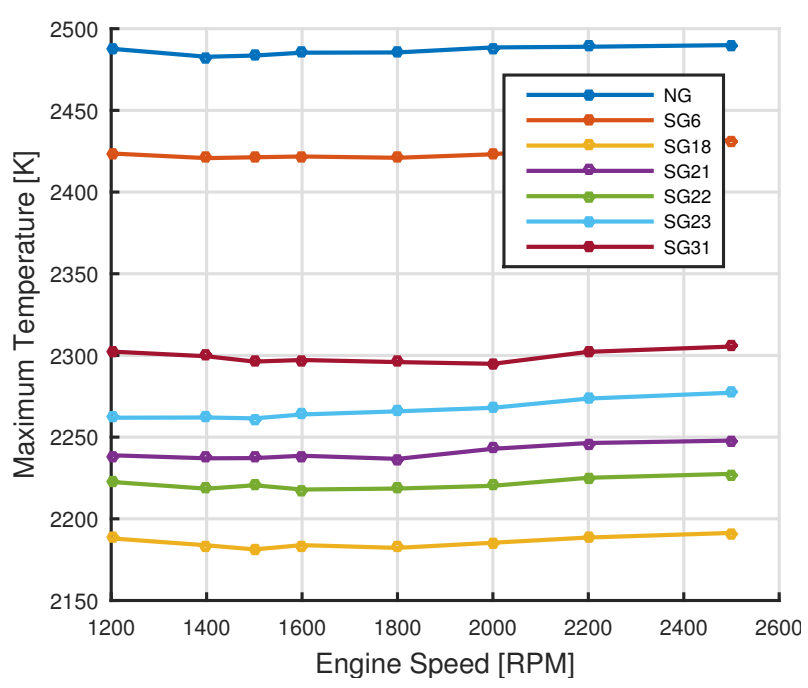

Figure 13. Maximum Cycle Temperature comparison of the 6 SGs with the NG fuel for the LGW 702 engine.

lower than for the NG (Figure 13). Thus, a lower tendency to produce $\mathrm{NO}_{x}$ is expected.

Finally, the maximum cycle pressure position (Figure 14) shows the effect of the CA50 optimization and a different Burn Duration for each fuel mixture: the values are shifting towards the TDC with growing engine speed, accordingly to the optimized CA50 position.

\section{Conclusions}

This paper presented a preliminary simulation study of the engine performance and combustion parameters running on six different syngas mixtures compared to natural gas.

A great part of the paper was focused on the numerical methods used for this preliminary analysis. Two different models - a closed-volume combustion analysis $1 C y l$ model and a Full model - were prepared and 


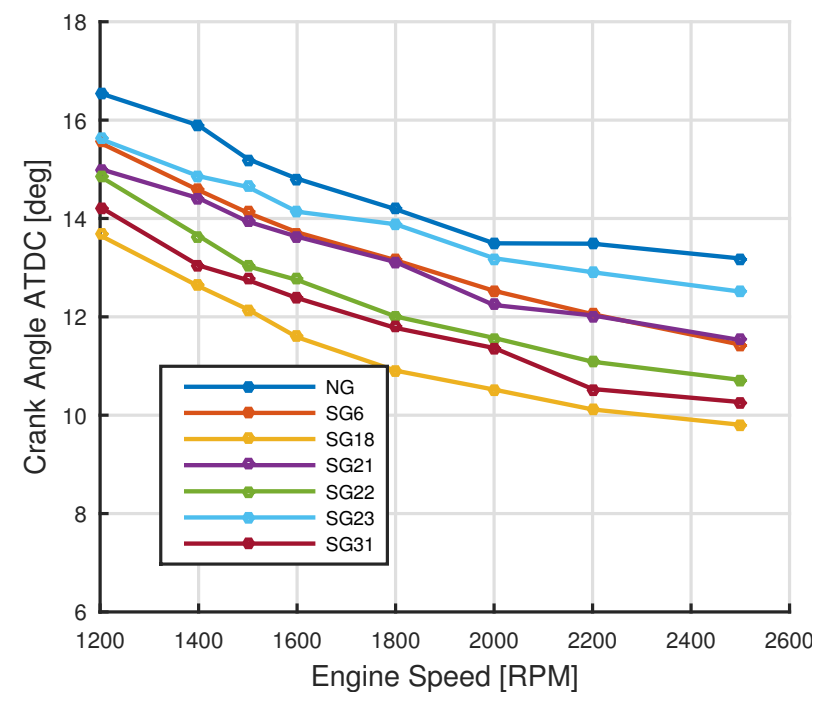

FIGURE 14. Maximum cycle pressure position comparison of the 6 SGs with the NG fuel for the LGW 702 engine.

used, with a special emphasis on the accurate combustion modelling, which was done with an in-house Empirical model based on Vibe and Csallner-Woschni formulas. This methodology expands our previous experimental work and goes in line with current research trends on alternative fuels.

The combustion analysis of the measured data using the $1 C y l$ model showed some dependencies of the burn duration and the burn profile shape on the mixture composition:

- hydrogen content in the fuel mixture affects the burn duration positively, speeding up the burning process; the inert gases act in opposite, slowing the process down;

- for the Group 2 mixtures, the effect of $\mathrm{H}_{2} / \mathrm{CH}_{4}$ (the SG22 and SG23) and $\mathrm{H}_{2} / \mathrm{CO}$ (the SG18 and $\mathrm{SG} 21)$ ratios on the burn duration is evident: more hydrogen means a faster burn;

- however, in order to get more accurate conclusions on burn duration trade-offs or the Vibe shape exponent, it is necessary to carry out a more detailed study on individual mixture components.

The results from the combustion analysis were used subsequently in the Empirical combustion model for the simulation of the LGW 702 operation on various syngas mixture compositions. To make use of the simulation model capabilities, we carried out the CA50 position optimization for each and every engine operating point. The obtained results from the simulation can be summarized in the following conclusions:

- all of the syngas mixtures show deteriorated overall performance and economy parameters compared to the NG, due to a high inert gas content and low LHV;

- the most favourable results are shown by the Group 1 syngas SG6 that also has the lowest inert gas content; the worst results are for Group 2, the syngas SG18, SG21, SG22 and SG23;

- regarding the IMEP values, the SG6 shows $11 \%$ drop to the NG and the SG23 shows approximately $30 \%$ drop to the NG values; ISFC difference varies from $+45 \%$ for SG22 to $+400 \%$ for SG18, compared to NG;

- a favourable result for all syngas mixtures is the decrease of the maximum cycle temperature, which leads to a lower $\mathrm{NO}_{x}$ production.

All of these results are promising, but our future work should focus on the refinement of our simulation models and especially on the Empirical combustion model verification. Generally speaking, this study provides a framework for the future studies of the alternative fuels performance parameters. Here presented methods will be applied on the whole range of thirty-five syngas mixtures. The measurements of those are already underway.

\section{LIST OF SYMBOLS}

a Vibe duration coefficient [1]

$m$ Vibe shape coefficient [1]

$p$ pressure [bar]

$\alpha$ crankshaft angle [deg]

$\lambda$ air excess [1]

CA50 $50 \%$ fuel burned [CA deg]

$T$ temperature $[\mathrm{deg}, \mathrm{K}]$

MFB mass fraction burned [1]

IMEP indicated mean effective pressure [bar]

ISFC indicated specific fuel consumption [ $\mathrm{g} / \mathrm{kWh}$ ]

$F$ criterial function [1]

$\alpha_{k}$ weight factor [1]

$X_{k}$ minimized function [1]

LHV lower heating value $[\mathrm{kJ} / \mathrm{kg}]$

\section{ACRONYMS}

1 Cyl single-cylinder combustion analysis model

Full full scale engine model

EVC exhaust valve closes

EVO exhaust valve opens

IVC inlet valve closes

IVO inlet valve opens

SI spark ignition engine

TDC top dead center

NG natural gas

$\mathrm{SG}$ syngas

$\mathrm{CH}_{4}$ methane molecule

$\mathrm{H}_{2}$ molecular hydrogen

$\mathrm{N}_{2}$ molecular nitrogen

$\mathrm{O}_{2}$ molecular oxygen

$\mathrm{CO}$ carbon monoxide

$\mathrm{CO}_{2}$ carbon dioxide

$\mathrm{NO}_{x}$ mono-nitrogen oxides ( $\mathrm{NO}$ and $\mathrm{NO}_{2}$ ) 


\section{ACKNOWLEDGEMENTS}

This work was supported by the Slovak Research and Development Agency under Contract-No. APVV-0015-12 and Contract-No. APVV-14-0399 and was also supported by the Scientific Grant Agency under the Contract No. VEGA 1/0017/14

\section{REFERENCES}

[1] Júlková, L., Ciahotný, K., Kusý, J., "Pyrolysis of Brown Coal Using a Catalyst Based on W-Ni," Acta Polytechnica 55(5):319-323, 2015, DOI: 10.14311/AP.2015.55.0319

[2] Lisý, M., Baláš, M. Špiláček, M., Skála, Z., "Operating Specifications of Catalytic Cleaning of Gas from Biomass Gasification," Acta Polytechnica 55(6):401-406, 2015, DOI: 10.14311/AP.2015.55.040

[3] Liu, C.C., Shy, S.S., Chiu, C.W., Peng, M.W. et al., "Hydrogen/carbon monoxide syngas burning rates measurements in high-pressure quiescent and turbulent environment", International Journal of Hydrogen Energy, 36(14): 8595-8603, 2011, DOI:10.1016/j.ijhydene.2011.04.087

[4] Herdin, G., Gruber, F., Klausner, J., Robitschko, R. et al., "Hydrogen and Hydrogen Mixtures as Fuel in Stationary Gas Engines," SAE Technical Paper 2007-01-0012, 2007, DOI:10.4271/2007-01-0012

[5] Feist, M., Landau, M., and Harte, E., "The Effect of Fuel Composition on Performance and Emissions of a Variety of Natural Gas Engines," SAE Int. J. Fuels Lubr. 3(2):100-117, 2010, DOI:10.4271/2010-01-1476

[6] Saanum, I., Bysveen, M., Tunestål, P., and Johansson, B., "Lean Burn Versus Stoichiometric Operation with EGR and 3-Way Catalyst of an Engine Fueled with Natural Gas and Hydrogen Enriched Natural Gas," SAE Technical Paper 2007-01-0015, 2007, DOI:10.4271/2007-01-0015

[7] Nellen, C. and Boulouchos, K., "Natural Gas Engines for Cogeneration: Highest Efficiency and

Near-Zero-Emissions through Turbocharging, EGR and 3-Way Catalytic Converter," SAE Technical Paper 2000-01-2825, 2000, DOI:10.4271/2000-01-2825

[8] Li, W., Liu, Z., Wang, Z., Li, C. et al., "Effect of CO2, N2, and Ar on Combustion and Exhaust Emissions Performance in a Stoichiometric Natural Gas Engine," SAE Technical Paper 2014-01-2693, 2014 DOI:10.4271/2014-01- 2693

[9] Neher, D., Kettner, M., Scholl, F., Klaissle, M. et al., "Numerical Investigations of a Naturally Aspirated Cogeneration Engine Operating with Overexpanded Cycle and Optimised Intake System," SAE Technical Paper 2014-32-0109, 2014, DOI:10.4271/2014-32-0109

[10] Hagos, F. and Abd Aziz, A., "Mass Fraction Burn Investigation of Lean Burn Low BTU Gasification Gas in Direct injection Spark-ignition Engine," SAE Technical Paper 2014-01-1336, 2014, DOI:10.4271/2014-01-1336

[11] Okafor, E., Fukuda, Y., Nagano, Y., and Kitagawa, T., "Turbulent Burning Velocities of Stoichiometric Hydrogen-Carbon Monoxide-Air Flames at Elevated Pressures," SAE Technical Paper 2014-01-2701, 2014 DOI:10.4271/2014-01-2701
[12] Orbaiz, P., Brear, M., Abbasi, P. and Dennis, P., "A Comparative Study of a Spark Ignition Engine Running on Hydrogen, Synthesis Gas and Natural Gas," SAE Int J. Engines 6(1):2013, DOI:10.4271/2013-01-0229

[13] Chríbik, A., Polóni, M., Ragan, B., Toman, R., "Some Results of Gas Mixture Influence on Combustion Course in Spark Ignition Engine," Proceedings of 18th International Conference "Transport Means 2014", October 23-24, 2014, Kaunas, ISSN 1822-296X.

[14] Chríbik, A., Polóni, M., Ragan, B., Toman, R., "The Influence of Biogas Composition on the Parameters of a Combustion Engine Running in Micro-Cogeneration Unit," ERIN, The 8th International Conference for Young Researchers and PhD Students, April 23-25, 2014, Blansko-Češkovice, Czech Republic.

[15] Polóni, M., Kálman, P., Lach, J., Smieško, Š., Lazar, L., Kunc, P., Jančošek, L., "Micro-cogeneration Unit with Variable-Speed Generator," International Scientific Event "Power Engineering 2010", May 18-20, 2010, Tatranské Matliare, High Tatras, Slovak Republic. 9th International Scientific Conference: Energy-EcologyEconomy (EEE) 2010, ISBN 978-80-89402-23-6.

[16] GT-POWER Engine Performance Application Manual. [Manual] Westmont: Gamma Technologies, Inc., 2015.

[17] Morel, T., Goerg, K.A., "Use of TPA (Three-Pressure Analysis) to Obtain Burn Rates and Trapped Residuals," GT-POWER User Conference, http: //www.gtisoft.com/publications/pub_conTP.php

[18] Vávra, J. and Takáts, M., "Heat Release Regression Model for Gas Fuelled SI Engines," SAE Technical Paper 2004-01-1462, 2004, DOI:10.4271/2004-01-1462

[19] Skarohlid, M., "Modeling of Influence of Biogas Fuel Composition on Parameters of Automotive Engines," SAE Technical Paper 2010-01-0542, 2010, DOI:10.4271/2010-01-0542

[20] Wahiduzzaman, S., Moral, T., and Sheard, S., "Comparison of Measured and Predicted Combustion Characteristics of a Four-Valve S.I. Engine," SAE Technical Paper 930613, 1993, DOI:10.4271/9306

[21] Morel, T., Keribar, R., "A Model for Predicting Spatially and Time Resolved Convective Heat Transfer in Bowl-in-Piston Combustion Chambers, " SAE Technical Paper 850204, 1985, DOI: 10.4271/850204

[22] Mirzaeian, M., Millo, F., and Rolando, L., "Assessment of the Predictive Capabilities of a Combustion Model for a Modern Downsized Turbocharged SI Engine", SAE Technical Paper 2016-01-0557, 2016, DOI:10.4271/2016-01-0557

[23] Vibe, I.I., "Semi-empirical expression for combustion rate in engines," In Proc. Conference on Piston Engines, USSR Academy of Sciences, Moscow, 1956

[24] Csallner, P., Woschni, G., "Zur Vorausberechnung des Brennverlaufes von Ottomotoren bei geanderten Betriebsbedingungen," MTZ No.5, 1982

[25] Lacina, V., "Použití modelu pracovního oběhu při vývoji plynového motoru." The dissertation thesis, ČVUT Praha 1988 
[26] Woschni, G., "Universally Applicable Equation for Instantaneous Heat Transfer Coefficient in the Combustion Engine," SAE Paper 670931, SAE Trans., vol.76, 1967

[27] Chríbik, A., "Parametre spalovacieho motora na zmes metánu a vodíka", The diploma thesis, STU Bratislava 2010
[28] Deb, K.; Pratap, A.; Agarwal, S.; Meyarivan, T. (2002). "A fast and elitist multiobjective genetic algorithm: NSGA-II". IEEE Transactions on Evolutionary Computation. 6(2): 182. DOI:10.1109/4235.996017 